\title{
Outcomes of limited proximal aortic replacement for type A aortic dissection in octogenarians
}

\author{
Haruhiko Kondoh, MD, PhD, ${ }^{a}$ Hisashi Satoh, MD, PhD, ${ }^{\text {a }}$ Takashi Daimon, $\mathrm{PhD},{ }^{\mathrm{b}}$ Yuuya Tauchi, MD, \\ Jumpei Yamamoto, MD, ${ }^{a}$ Kazuo Abe, $\mathrm{MD}, \mathrm{PhD},{ }^{\mathrm{c}}$ and Hikaru Matsuda, $\mathrm{MD}, \mathrm{PhD}^{\mathrm{a}}$
}

\section{ABSTRACT}

Objective: The number of older patients with acute aortic dissection type A (AAD $[\mathrm{A}]$ ) is increasing as the population ages. We evaluated clinical outcomes for octogenarians with AAD (A) treated surgically at our hospital. Whenever possible, we limited the replacement site of the ascending aorta to the supracoronary and hemiarch.

Methods: Of 436 patients with AAD (A) seen in our hospital emergency room between April 2001 and August 2015, 90 were octogenarians. Surgery was performed using a simple cardiopulmonary bypass established through the right femoral artery and venous cannulation, and distal anastomosis was performed under deep hypothermic circulatory arrest at $20^{\circ} \mathrm{C}$.

Results: Of the 90 octogenarians with AAD (A), 11 required cardiopulmonary resuscitation, 9 of whom died. Four patients with stable hemodynamics refused surgery. Thus, 77 were treated surgically. Of these 77 patients, isolated replacement of the ascending aorta or hemiarch was performed in $73(94.8 \%)$, and total arch replacement in $4(5.2 \%)$. Five patients $(6.5 \%)$ died within 30 days, and 5 $(6.5 \%)$ died in the hospital more than 30 days after surgery. Seven $(9.1 \%)$ had a new stroke, $5(6.5 \%)$ had pneumonia, and $4(5.2 \%)$ had mediastinitis. Fortyfour $(57.1 \%)$ patients were discharged to their homes and $23(30 \%)$ to rehabilitation hospitals. Three patients later required endovascular stent graft repair, which was successful in each case. The overall postoperative survival was $82 \%, 70 \%$, and $62 \%$ at 1,3 , and 5 years, respectively.

Conclusions: Our results suggest that our limited replacement protocol for emergency AAD (A) surgery has early and midterm survival benefits for octogenarians. (J Thorac Cardiovasc Surg 2016;152:439-46)

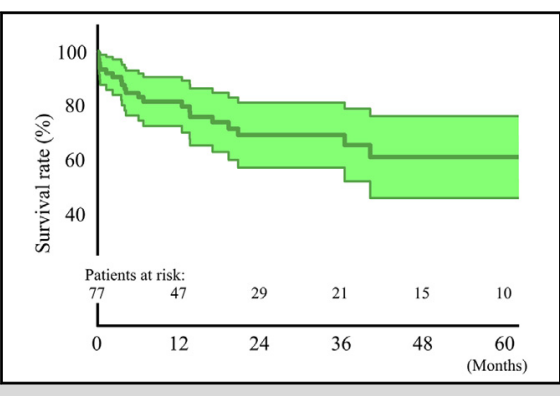

Survival in octogenarians with acute aortic dissection repair.

\section{Central Message}

For type A acute aortic dissection, isolated replacement of the ascending aorta provides favorable results in octogenarians.

\section{Perspective}

We evaluated surgical outcomes for 77 octogenarians with type A acute aortic dissection (AAD [A]). Our surgical strategy, applied consistently for 14 years, is to limit the procedure to isolated replacement of the ascending aorta, between the supracoronary and the hemiarch, whenever possible. This strategy led to satisfactory outcomes in octogenarians with AAD (A).

See Editorial Commentary page 447
The World Population Ageing 2013 report $^{1}$ by the United Nations Department of Economic and Social Affairs showed that the population of octogenarians is increasing as a result of increases in life span and birth rate and that within the older population (aged 60 years or older), the proportion of persons 80 years or older increased from $7 \%$ in 1950 to $14 \%$ in 2013. In Japan, the number of people 80 years or older increased from 4.86 million in 2000 to 9.3

\footnotetext{
From Departments of ${ }^{\mathrm{a}}$ Cardiovascular Surgery and ${ }^{\mathrm{c}}$ Anesthesiology, Higashi Takarazuka Satoh Hospital, Nagao-cho, Takarazuka; and ${ }^{\mathrm{b}}$ Department of Biostatistics, Hyogo College of Medicine, Mukogawa-cho, Nishinomiya, Hyogo, Japan.

Received for publication Oct 23, 2015; revisions received Feb 23, 2016; accepted for publication March 12, 2016; available ahead of print May 7, 2016.

Address for reprints: Haruhiko Kondoh, MD, PhD, Department of Cardiovascular Surgery, Higashi Takarazuka Satoh Hospital 2-1, Nagao-cho, Takarazuka, Hyogo 665-0873, Japan (E-mail: haruhk@wa3.so-net.ne.jp).

$0022-5223 / \$ 36.00$

Copyright (c) 2016 by The American Association for Thoracic Surgery http://dx.doi.org/10.1016/j.jtcvs.2016.03.093
}

million in $2013 .^{2}$ Although this aging of the population reflects a trend toward longer and generally healthier lives, the prevalence of chronic and degenerative diseases at older ages also increases. Thus, the number of octogenarians referred for major aortic surgery has also increased.

Type A acute aortic dissection (AAD [A]) is a severe, life-threatening disease with high overall mortality when untreated. $^{3}$ The surgical treatment of AAD (A) is challenging, especially in older patients. In octogenarians with AAD (A), postoperative mortality of $45.5 \%$ to $83.3 \%$ was reported between 2001 and $2009 .{ }^{4-8}$ Although a less

Scanning this $\mathrm{QR}$ code will take you to the article title page. 


\section{Abbreviations and Acronyms}
$\mathrm{AAD}(\mathrm{A})=$ acute aortic dissection type $\mathrm{A}$
ER = emergency room
$\mathrm{CT}=$ computed tomography
$\mathrm{CPA}=$ cardiopulmonary arrest
$\mathrm{CPR}=$ cardiopulmonary resuscitation
$\mathrm{CABG}=$ coronary artery bypass grafting
AVR = aortic valve replacement
TEVAR $=$ thoracic endovascular aortic repair

invasive surgical strategy may benefit elderly patients with AAD (A), it has not been determined whether a limited or extended aortic replacement site produces better surgical results. In addition, the procedures for managing perfusion, temperature, and protection of the brain during surgery for AAD (A) have not been established for octogenarians. Thus far, reports of surgical outcomes for AAD (A) in octogenarians have evaluated only small numbers of patients. ${ }^{9,10}$

Here we report our institution's experience in treating octogenarians who were admitted to our hospital emergency room (ER) with AAD (A) during the past 14 years, including outcomes for our institutional strategy, which covers patient selection, the surgical procedure, and perfusion and temperature management.

\section{METHODS}

\section{Patients}

We retrospectively evaluated 436 consecutive patients, including 90 octogenarians, who were admitted through our ER and treated for AAD (A) from April 2001 to August 2015. This study reports outcomes for the 90 octogenarians.

\section{Strategy for Selecting ER Patients for Surgery}

All patients were diagnosed with AAD (A) by echocardiogram or enhanced computed tomography (CT), either at our hospital or at a previous hospital. Patients who arrived at the ER with cardiopulmonary arrest (CPA) received cardiopulmonary resuscitation (CPR) and were intubated, given catecholamine, and treated by subxiphoid pericardial drainage for pericardial effusion associated with pericardial tamponade as necessary.

For patients with $\mathrm{CPA}$, emergency surgery for $\mathrm{AAD}(\mathrm{A})$ was performed only after successful CPR. In patients with stroke, surgery for AAD (A) was performed only after the patient recovered from the stroke. Informed consent was obtained before surgery. Our selection process and the number of patients selected are shown in Figure 1. Of 79 patients without CPA and 2 patients successfully treated by CPR after CPA, 4 (5.1\%) rejected surgical treatment and $77(94.9 \%)$ were treated surgically. The patients' clinical characteristics are summarized in Table 1.

\section{Surgical Strategy}

Extensive aortic surgery including the aortic arch or root surgery is determined according to an aortic-tear-based paradigm for patients younger than 80 years. However, for AAD (A) in octogenarians, our strategy is to limit the procedure to isolated replacement of the ascending aorta, between the supracoronary and the hemiarch, whenever possible. Total

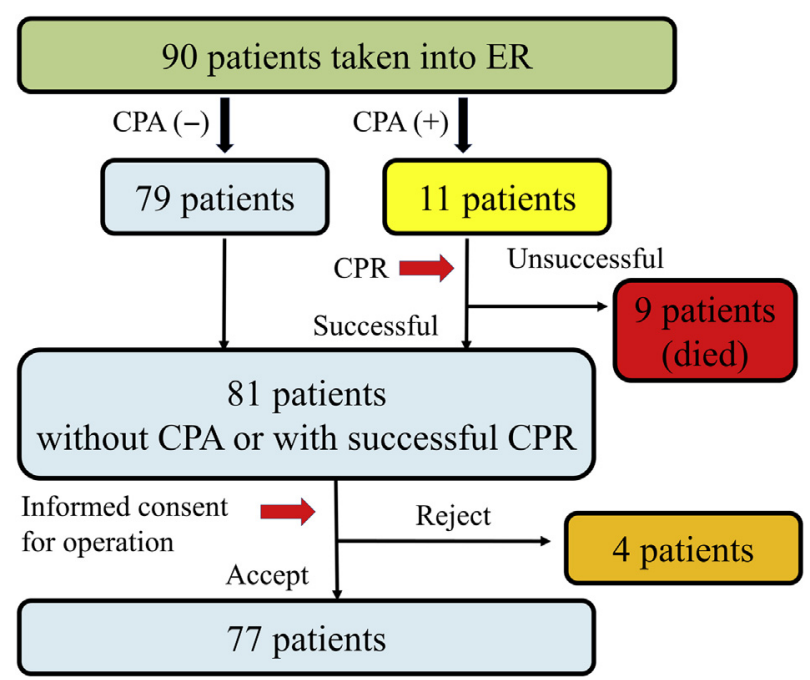

FIGURE 1. Selection process and number of patients. $E R$, Emergency room; $C P A$, cardiopulmonary arrest; $C P R$, cardiopulmonary resuscitation.

arch replacement is performed only in patients with an arch aneurysm greater than $60 \mathrm{~mm}$ in diameter or a rupture of the aortic arch.

\section{Intraoperative Monitoring}

The right radial artery and left common femoral arteries were cannulated for continuous blood pressure monitoring and early warning of malperfusion. Temperature probes were placed to monitor the esophagopharyngeal and bladder temperatures, and near-infrared spectroscopy was used for neurovascular monitoring to assess cerebral perfusion.

\section{Surgical Technique}

Patients were placed on cardiopulmonary bypass, established with arterial return to the right common femoral artery, which was cannulated with a flexible arterial cannula, and venous drainage through the right atrium, which was cannulated with a venous cannula from the right femoral vein, and cooled to reach a bladder temperature of $20^{\circ} \mathrm{C}$ or a pharyngeal temperature of $16^{\circ} \mathrm{C}$. While cooling the patient, we performed a median sternotomy and inserted a left ventricular vent tube and retrograde cardioplegia cannula. Systemic perfusion was discontinued when the patient reached a bladder temperature of $20^{\circ} \mathrm{C}$ or pharyngeal temperature of $16^{\circ} \mathrm{C}$.

The ascending aorta was transversely resected, and the segment containing the intimal tear was replaced within the limit of the supracoronary ascending aorta to the hemiarch. If the intimal tear was located in the distal arch to the descending aorta, only the ascending aorta was replaced.

Distal anastomosis was performed at the base of the innominate artery between a 1-branched graft (Hemashield Platinum [Maquet Cardiovascular LLC, Wayne, NJ], J Graft Shield Neo [Japan Lifeline Co Ltd, Tokyo, Japan], or a Triplex graft [Terumo Co Ltd, Tokyo, Japan]) and the distal ascending aorta; anastomosis was performed within 30 minutes under an open distal condition without cerebral perfusion. After completing distal anastomosis, we began rewarming the patient by an arterial return through a 1-branch graft.

The ascending aorta was transected at the sinotubular level, and gelatin resorcin formalin glue or bio-glue (CryoLife Inc, Kennesaw, Ga) was applied between the 2 dissected walls of the aorta if the dissection extended to the sinus of Valsalva. Resuspension of the aortic valve and proximal anastomosis at this reconstructed sinotubular junction level were performed.

For the distal and proximal ascending aortic anastomosis, the surgeon chose adventitial inversion ${ }^{11}$ or conventional reconstruction by reapproximating the dissected aortic layers with Teflon (Impra Inc, Tempe, Ariz) felt-strip reinforcement both inside and outside the aorta. 
TABLE 1. Preoperative patient characteristics

\begin{tabular}{lc}
\hline \multicolumn{1}{c}{ Characteristic } & $\begin{array}{c}\text { Number }(\%) \text { or } \\
\text { median } \\
\text { (range) }(\mathbf{N}=\mathbf{7 7})\end{array}$ \\
\hline Age $(\mathrm{y})$ & $83(80-89)$ \\
Men/women & $18(23) / 59(77)$ \\
Body mass index $\left(\mathrm{kg} / \mathrm{m}^{2}\right)$ & $20.8(12.2-31.1)$ \\
Coronary artery disease & $6(7.8)$ \\
Old cerebrovascular disease & $8(10.4)$ \\
Low ejection fraction $<35 \%$ & None \\
Renal failure $($ estimated glomerular filtration rate & $5(6.5)$ \\
$\quad<30$ mL/min/1.73 $\left.{ }^{2}\right)$ & \\
Previous cardiac operation & $1(1.3)$ \\
Previous abdominal aortic aneurysm repair & $7(9.1)$ \\
Stigmata to Marfan syndrome & None \\
Annuloaortic ectasia/Valsalva sinus aneurysm & None \\
Aortic valve regurgitation $>$ second degree & $7(9.1)$ \\
Aortic valve stenosis & $1(1.3)$ \\
Cardiopulmonary arrest & $2(2.6)$ \\
Shock (intubation or catecholamine & $9(11.7)$ \\
$\quad$ administration) & \\
Tamponade & $28(36.4)$ \\
Malperfusion syndrome & $2(2.6)$ \\
Entry in ascending aorta & $48(62.3)$ \\
DeBakey type I/II & $60(78) / 17(22)$ \\
Additive EuroSCORE & $13(11-20)$ \\
Logistic EuroSCORE $(\%)$ & $42.3(21.6-86.2)$ \\
\hline
\end{tabular}

When indicated, total arch replacement was performed by an elephanttrunk technique, an arch-first technique via a median sternotomy, or a clamshell incision, at the surgeon's discretion. ${ }^{12,13}$ The aortic valve was replaced, if necessary, after distal aortic anastomosis. Associated coronary artery bypass grafting (CABG), if necessary, was performed after proximal aortic anastomosis.

\section{Postoperative Mortality and Morbidity}

A neurologic complication was defined as the presence of a new focal or global deficit, and was confirmed by $\mathrm{CT}$ or magnetic resonance imaging of the brain. Thirty-day mortality was defined as death within 30 days after surgery, whether the patient was still hospitalized or had been discharged. Hospital mortality was defined as death occurring during the initial hospitalization more than 30 days after surgery. Early postoperative adverse events were defined as 30-day mortality, hospital mortality, re-exploration for bleeding, neurologic complications, pneumonia, and mediastinitis.

\section{Follow-up}

All patients underwent a CT scan within 1 month after surgical intervention. All the living patients were then followed on an outpatient basis with annual serial CT scans or by telephone to evaluate their clinical status.

\section{Statistical Analysis}

Continuous and categorical variables are expressed as medians with ranges and as frequencies with percentages, respectively. In univariate analyses, continuous and categorical variables were compared using the Mann-Whitney $U$ test and Fisher exact test, respectively. In multivariate analyses, logistic regression analysis was performed to identify risk factors for early postoperative adverse events, where variables with $P$ values less than .2 in the univariate analyses were included. The following variables were examined: age, gender, CPA, shock, malperfusion, tamponade, aortic valve regurgitation (greater than second degree), estimated glomerular filtration rate, old cerebrovascular disease, logistic EuroScores, entry site of aortic dissection, and total arch replacement. The results are shown as odds ratios, 95\% confidence intervals, and $P$ values. Survival curves were estimated using Kaplan-Meier methods and compared using the log-rank test. All tests were 2 -sided, and statistical significance was set at .05 . Statistical analyses were performed using JMP, version 7.0 (SAS Institute, Cary, NC).

\section{RESULTS \\ Perioperative Results}

The surgical procedures are summarized in Table 2. Following our surgical strategy, $73(94.8 \%)$ patients were treated by isolated ascending aortic replacement, and 4 $(5.2 \%)$ by total arch replacement. Aortic valve resuspension was performed in all patients except 1 , who received an aortic valve replacement. Concomitant procedures were planned for only 2 patients; 1 surgery included $\mathrm{CABG}$ for severe isolated stenosis in the proximal left anterior descending coronary artery and the other included aortic valve replacement for severe aortic valve stenosis. Unplanned CABG with mitral annuloplasty was performed in 1 case after it became apparent that the patient could not be weaned from the cardiopulmonary bypass because of severe hypokinesis of the anterior septal part of the left ventricle and severe mitral regurgitation. Of the 4 patients treated by total arch replacement, 3 had an aortic arch aneurysm greater than $60 \mathrm{~mm}$ in diameter and 1 had an aortic arch rupture.

The right femoral artery was directly cannulated in 72 patients $(98.6 \%)$ treated with an isolated ascending aorta replacement. Femoral artery cannulation was avoided in 1 patient because of a severely shaggy aorta. In 3 patients, the ascending aorta was also cannulated as a result of malperfusion when starting the cardiopulmonary bypass with an arterial return only from the right femoral artery cannulation. In all 4 patients with total arch replacement, both the femoral artery and the right axillary artery were initially cannulated. The right femoral vein was directly cannulated into the right atrium in 74 patients. Nine patients required additional venous cannulation into the superior vena cava because of inadequate venous drainage to the cardiopulmonary bypass. The right femoral vein could not be used in 3 patients, because of a tortuous configuration in 2 and an injury to the right iliac vein in 1 .

\section{Early Outcomes and Postoperative Complications}

The 30-day mortality was $6.5 \%$ (5 patients). Two of these patients required percutaneous cardiopulmonary support during surgery: one had massive pulmonary bleeding and the other had an intraoperative myocardial infarction resulting in severe ventricular dysfunction. The hospital mortality was $6.5 \%$ (5 patients). Two of these patients died from rupture of the descending aorta beyond the carina level, on the fourth and eleventh postoperative day. Both patients had a descending aortic aneurysm greater than $50 \mathrm{~mm}$ in diameter with aortic dissection extending to the terminal 
TABLE 2. Operative and postoperative characteristics

\begin{tabular}{|c|c|c|}
\hline & $\begin{array}{c}\text { Isolated ascending } \\
\text { aorta/hemiarch } \\
(\mathrm{N}=73)(94.8 \%)\end{array}$ & $\begin{array}{c}\text { Total arch } \\
\text { replacement } \\
(\mathrm{N}=4)(5.2 \%) \\
\end{array}$ \\
\hline \multicolumn{3}{|l|}{ Associated procedure } \\
\hline $\begin{array}{l}\text { Aortic valve resuspension, } \\
\mathrm{n}(\%)\end{array}$ & $72(98.6)$ & $4(100)$ \\
\hline AVR, n (\%) & $1(1.4)$ & None \\
\hline CABG, n (\%) & $1(1.4)$ & None \\
\hline CABG + MAP, n (\%) & $1(1.4)$ & None \\
\hline Aortic root surgery & None & None \\
\hline \multicolumn{3}{|l|}{ Arterial cannulation site } \\
\hline FA only, n (\%) & $69(94.5)$ & 0 \\
\hline $\mathrm{FA}+$ ascending aorta, $\mathrm{n}(\%)$ & $3(4.1)$ & 0 \\
\hline Ascending aorta only, n (\%) & $1(1.4)$ & 0 \\
\hline Axillary artery + FA, n (\%) & None & $4(100)$ \\
\hline \multicolumn{3}{|l|}{ Venous cannulation site } \\
\hline FV only, n (\%) & $63(86.3)$ & $2(50)$ \\
\hline $\mathrm{FV}+\mathrm{SVC}$ or RA, n $(\%)$ & $7(9.6)$ & $2(50)$ \\
\hline $\mathrm{SVC}+\mathrm{IVC}, \mathrm{n}(\%)$ & $3(4.1)$ & 0 \\
\hline $\begin{array}{l}\text { Operation time (min), median } \\
\quad \text { (range) }\end{array}$ & $294(178-539)$ & $488(345-580)$ \\
\hline CPB time (min), median (range) & $172(101-381)$ & $239(200-341)$ \\
\hline $\begin{array}{l}\text { Myocardial ischemic time (min), } \\
\text { median (range) }\end{array}$ & $89(39-175)$ & $114(89-175)$ \\
\hline $\begin{array}{l}\text { Systemic CA time (min), median } \\
\text { (range) }\end{array}$ & $29(16-45)$ & \\
\hline
\end{tabular}

\begin{tabular}{lcc}
$\quad \begin{array}{c}\text { Type of total } \\
\text { arch replacement }\end{array}$ & Arch first $(\mathbf{N}=\mathbf{3})$ & ET $(\mathbf{N}=\mathbf{1})$ \\
\hline $\begin{array}{l}\text { Lowest body temperature }\left({ }^{\circ} \mathrm{C}\right), \\
\text { median (range) }\end{array}$ & $20(19-21)$ & 24 \\
$\begin{array}{l}\text { Systemic CA time (min), median } \\
\quad(\text { range) }\end{array}$ & $22(14-39)$ & 0 \\
$\begin{array}{l}\text { SCP time (min), median (range) } \\
\text { Lower body CA time (min), } \\
\text { median (range) }\end{array}$ & $42(37-111)$ & 96 \\
\hline
\end{tabular}

$\overline{A V R}$, Aortic valve replacement; $C A B G$, coronary artery bypass grafting; $M A P$, mitral annuloplasty; $F A$, femoral artery; $F V$, femoral vein; $S V C$, supra vena cava; $R A$, right atrium; $I V C$, inferior vena cava; $C P B$, cardiopulmonary bypass; $C A$, circulatory arrest; $E T$, elephant trunk; $S C P$, selective cerebral perfusion.

aorta. The location of entry in these patients was the ascending aorta and distal arch. Table 3 lists all causes of death.

Five patients $(6.5 \%)$ had to be re-explored for bleeding, and a new stroke occurred in 7 patients $(9.1 \%)$. Of 5 patients $(6.5 \%)$ who developed pneumonia, there were 3 cases of 30-day or hospital mortality. Of $4(5.2 \%)$ patients with mediastinitis, there was 1 case of 30-day or hospital mortality. The median hospital stay among surviving patients was 45 (18-474) days. Eighteen patients $(23.4 \%)$ had a hospital stay of more than 90 days. Many of these patients had postoperative morbidities (mediastinitis 3, re-exploration 2, pneumoniae 1, and neurologic complications 5). Fortyfour patients $(57 \%)$ were discharged without any care. Of
TABLE 3. Early operative results

\begin{tabular}{lc}
\hline \multicolumn{1}{c}{ Characteristics } & Number $(\%)(\mathbf{N}=\mathbf{7 7})$ \\
\hline Early death $(\leq 30 \mathrm{~d})$ & $5(6.5)$ \\
Rupture (distal arch) & 2 \\
Pulmonary bleeding & 1 \\
Perioperative myocardial infection & 1 \\
Pneumonia & 1 \\
Hospital death (>30 d) & $5(6.5)$ \\
Pneumonia & 2 \\
Mediastinitis & 1 \\
Bowel ischemia & 1 \\
Low output syndrome & 1 \\
Morbidity & $5(6.5)(2)^{*}$ \\
Re-exploration for bleeding & $7(9.1)(1)^{*}$ \\
Neurologic complications & $5(6.5)(3)^{*}$ \\
Pneumonia & $4(5.2)(1)^{*}$ \\
Mediastinitis & $38(49.3)$ \\
Extubation within 72 hours & $8(10.4)$ \\
Tracheostomy & $2(2.6)$ \\
Acute renal failure requiring new & \\
hemodialysis & $18(23.4)$ \\
Hospital stay $>90 \mathrm{~d}$ & $44(57.1)$ \\
Home without other care & $23(29.9)$ \\
Rehabilitation hospital & $11(14.3)$ \\
Discharge to home from rehabilitation & \\
hospital & \\
*Number of patients with 30-day or in-hospital death. &
\end{tabular}

$23(30 \%)$ patients discharged to a rehabilitation hospital, 11 were later discharged to their home.

\section{Analysis of Risk Factors for Adverse Events}

The influence of patients' preoperative characteristics on early postoperative adverse events was examined. Multivariate analysis showed male gender and preoperative tamponade to be the only significant risk factors for postoperative adverse events (Table 4 ).

\section{Additional Surgery Associated With Aortic Dissection}

There were no cases of proximal redissection during the follow-up. Additional procedures associated with aortic dissection were performed with endovascular stent graft repair in 3 patients (Table 5); these procedures were successful in all cases. In 1 patient, thoracic endovascular aortic repair (TEVAR) was performed for sudden-onset malperfusion in the right lower extremity 16 days after the initial AAD (A) operation. Another patient required endovascular aortic repair for an abdominal aortic aneurysm 9 months after the initial AAD (A) operation. One patient required 2 debranching TEVARs for a distal arch aneurysm 27 months after the initial AAD (A) operation.

\section{Late Survival}

Table 5 shows the causes of late deaths. No deaths were known to be related to the aortic dissection, although 3 
TABLE 4. Risk factors for early postoperative adverse events

\begin{tabular}{|c|c|c|c|c|c|c|}
\hline \multirow[b]{2}{*}{ Variables } & \multicolumn{3}{|c|}{ Univariate analysis } & \multicolumn{3}{|c|}{ Multivariate analysis } \\
\hline & $\begin{array}{c}\text { No adverse } \\
\text { events }(\mathbf{N}=\mathbf{5 5})\end{array}$ & $\begin{array}{c}\text { Adverse } \\
\text { events }(N=22)\end{array}$ & $P$ value & Odds ratio & $\begin{array}{l}95 \% \text { confidence } \\
\text { interval }\end{array}$ & $P$ value \\
\hline Age (y) & $83(80-89)$ & $84(80-87)$ & .390 & & & \\
\hline Male & $9(16)$ & $9(41)$ & .0215 & 6.341 & $1.767-22.755$ & .0046 \\
\hline Cardiopulmonary arrest & $2(4)$ & $0(0)$ & 1.000 & & & \\
\hline Shock & $5(9)$ & $4(18)$ & .2622 & & & \\
\hline Malperfusion & $2(4)$ & $0(0)$ & 1.000 & & & \\
\hline Tamponade & $14(25)$ & $14(64)$ & .0017 & 6.206 & $1.835-20.992$ & .0033 \\
\hline Aortic valve regurgitation $>2$ degree & $6(11)$ & $3(14)$ & .7094 & & & \\
\hline $\begin{array}{l}\text { Estimated glomerular filtration rate } \\
\qquad\left(\mathrm{mL} / \mathrm{min} / 1.73 \mathrm{~m}^{2}\right), \text { median (range) }\end{array}$ & $58.4(17.4-105)$ & $55.1(7.3-104)$ & .1713 & 1.003 & $0.9755-1.031$ & .8344 \\
\hline Old cerebrovascular disease & $5(9)$ & $3(14)$ & .4117 & & & \\
\hline EuroSCORE, $\%$ median (range) & $40.6(21.6-72.8)$ & $43.1(28.7-86.2)$ & .3283 & & & \\
\hline Entry in ascending aorta & $34(62)$ & $14(64)$ & .8818 & & & \\
\hline Total arch replace & $2(4)$ & $2(9)$ & .5735 & & & \\
\hline
\end{tabular}

Values are number $(\%)$

patients died of unknown causes. The first 6 late deaths occurred within 15 months after AAD (A) surgery; all 6 patients had been discharged to a rehabilitation hospital. The survival rates were $82 \%, 70 \%$, and $62 \%$ at 1,3 , and 5 years, respectively (Figure 2). By gender, the survival rates for women were $85 \%, 74 \%$, and $63 \%$ at 1,3 , and 5 years, and those for men were $71 \%, 57 \%$, and $57 \%$ at 1,3 , and 5 years, respectively (Figure 2). The age at the time of surgery was similar for women $(\mathrm{n}=59$; age, 82.5 (80-87) years $)$ and men $(n=18$; age, 83.0 (80-89) years;
$P=.28)$. Survival after surgery was slightly better for women than for men, but the difference did not reach statistical significance $(P=.3155)$ (Figure 2$)$.

\section{DISCUSSION}

This study shows that our surgical strategy for AAD (A) led to satisfactory outcomes in octogenarians. This strategy involves limiting the replacement area of the ascending aorta to the supracoronary and the hemiarch whenever possible.

TABLE 5. Additional aorta-related procedures and causes of late operative mortality

\begin{tabular}{|c|c|c|c|c|c|}
\hline Age $(y)$ & Sex & AAD operation & Diagnosis & Procedure & $\begin{array}{c}\text { After initial } \\
\text { operation (mo) }\end{array}$ \\
\hline \multicolumn{6}{|c|}{ Additional aorta-related procedure } \\
\hline 80 & $\mathrm{~F}$ & Ascending aorta & Malperfusion (lower extremity) & TEVAR & 0.5 \\
\hline 83 & $\mathrm{~F}$ & Ascending aorta & AAA & EVAR & 9 \\
\hline 81 & M & Ascending aorta & Arch aneurysm & 2 debranching TEVAR & 27.5 \\
\hline Age* & Sex & AAD operation $†$ & Discharge after AAD operation & Cause of death & $\begin{array}{c}\text { Survival after AAD } \\
\text { operation (mo) }\end{array}$ \\
\hline \multicolumn{6}{|c|}{ Cause of late mortality } \\
\hline 82 & M & Ascending aorta & RH & Pneumonia & 3.6 \\
\hline 80 & $\mathrm{~F}$ & TAR & RH & Pneumonia & 4.0 \\
\hline 82 & $\mathrm{~F}$ & Ascending aorta & RH & Pneumonia & 6.0 \\
\hline 84 & $\mathrm{~F}$ & TAR & RH & Unknown & 12.4 \\
\hline 83 & M & Ascending aorta & RH & Unknown & 13.5 \\
\hline 86 & M & Ascending aorta & RH & Unknown & 13.6 \\
\hline 83 & $\mathrm{~F}$ & Ascending aorta & Home & Pneumonia & 16.9 \\
\hline 87 & $\mathrm{~F}$ & Ascending aorta & RH & Pneumonia & 19.3 \\
\hline 80 & $\mathrm{~F}$ & Ascending aorta & Home & Cerebral bleeding & 20.7 \\
\hline 86 & $\mathrm{~F}$ & Ascending aorta & Home & Aging & 36.3 \\
\hline 80 & $\mathrm{~F}$ & Ascending aorta & Home & Aging & 40.1 \\
\hline 86 & $\mathrm{~F}$ & Ascending aorta & Home & Pneumonia & 70.3 \\
\hline 84 & $\mathrm{~F}$ & Ascending aorta & $\mathrm{RH}$ & Aging & 78.4 \\
\hline
\end{tabular}

$A A D$, Acute aortic dissection; $F$, female; $T E V A R$, thoracic endovascular aortic repair; $A A A$, abdominal aortic aneurysm; $E V A R$, endovascular aortic repair; $M$, male; $R H$, rehabilitation hospital; TAR, total arch replacement. *Age at initial AAD (A) operation. $\nmid$ Types of initial operation of acute aortic dissection. 


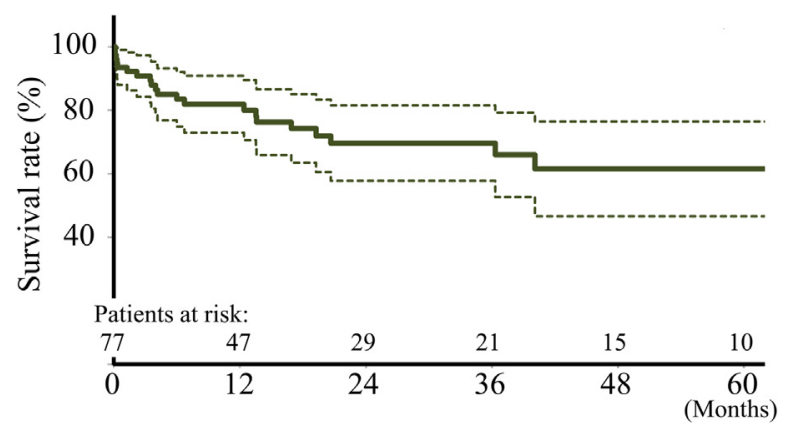

A

\begin{tabular}{c|c|c|c|} 
Survival & 1 -Year $(95 \% \mathrm{CI})$ & 3 -Year $(95 \% \mathrm{CI})$ & 5 -Year $(95 \% \mathrm{CI})$ \\
\hline
\end{tabular}

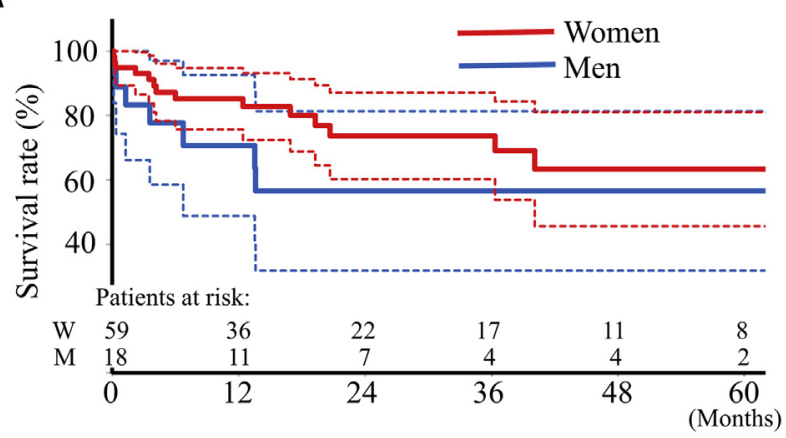

\begin{tabular}{|l|c|c|c|}
\hline Survival & 1 -Year $(95 \% \mathrm{CI})$ & 3-Year (95\%CI) & 5 -Year $(95 \% \mathrm{CI})$ \\
\hline
\end{tabular}

\begin{tabular}{|l|l|l|l|}
\hline Women & $85 \%(76 \%-95 \%)$ & $74 \%(60 \%-87 \%)$ & $63 \%(46 \%-81 \%)$
\end{tabular}

B

\begin{tabular}{|l|l|l|l|} 
Men & $\mathbf{7 1} \%(49 \%-93 \%)$ & $57 \%(32 \%-81 \%)$ & $57 \%(32 \%-81 \%)$
\end{tabular}

FIGURE 2. Survival rates after surgery for acute aortic dissection. A, Overall patient survival rate. B, Survival rate by gender. Although the age at the time of surgery was similar for women $(n=59$; age, 83 years; range, $80-89$ years) and men $(n=18$; age, 82.5 years; range, $80-87$ years; $P=.28$ ), women had a slightly better survival rate. However, the difference did not reach statistical significance $(P=.3155)$. $C I$, Confidence interval; $M$, men; $W$, women.

\section{Thirty-Day Mortality}

Since 2001, several studies ${ }^{4-10,14,15}$ have reported outcomes for the surgical treatment of AAD (A) in octogenarians. Reports from 2001 to 2009 found unsatisfactory survival rates, ranging from $45.5 \%$ to $83.3 \%$, for octogenarians after surgery for $\mathrm{AAD}(\mathrm{A})$, and significantly higher in-hospital mortality for octogenarians than for younger patients. ${ }^{4-7}$ Therefore, the surgical treatment for AAD (A) in octogenarians is controversial. However, since 2010, excellent surgical outcomes for AAD (A) have been reported even for octogenarians, with an in-hospital mortality of $0 \%$ to $3.7 \%{ }^{9,10}$ These reports cannot be compared strictly based on in-hospital mortality; other factors such as sample size, the number of patients who presented with CPA or declined surgery, and each patient's clinical status on admission to the ER can strongly affect surgical outcomes and survival.

\section{Preoperative Patient Status}

The preoperative clinical severity, including such factors as shock, CPA, or malperfusion syndrome, deeply affects the morbidity and mortality after surgical treatment for AAD (A). ${ }^{16,17}$ El-Sayed Ahamed et al. ${ }^{15}$ reported a 30day mortality of $26 \%$ in 39 octogenarians surgically treated for AAD (A); these patients included 7 cases $(18 \%)$ of shock, $7(18 \%)$ with malperfusion, and $2(5 \%)$ with CPA. Tang et al. ${ }^{10}$ reported excellent surgical outcomes in 21 octogenarians with AAD (A); however, their report included only 2 cases $(9.5 \%)$ of shock, $1(4.8 \%)$ with malperfusion, and none with CPA. Following our strategy for octogenarians with AAD (A) in critical condition, we performed standard CPR and intubation, catecholamine administration, and subxiphoid pericardial drainage for pericardial effusion associated with pericardial tamponade, as necessary. Even when patients were in critical condition, we did not transport them to the operating room until they had recovered from CPA, and we did not operate without obtaining informed consent. Consequently, the percentage of highseverity cases was low, with only 9 patients $(11.7 \%)$ with shock, $2(2.6 \%)$ with malperfusion, and $2(2.6 \%)$ with CPA recovery among the 77 patients who received surgical treatment; this probably contributed to our satisfactory surgical result outcomes.

\section{Risk Factors for Early Postoperative Adverse Events}

Malperfusion and CPA are known risk factors for postoperative adverse events after surgery for $\operatorname{AAD}(\mathrm{A}){ }^{16,17}$ However, in our study, both univariate and multivariate analysis showed male gender and preoperative tamponade as the only significant risk factors for postoperative adverse events. This was probably because of the low percentage of high-severity cases, including those with CPA or malperfusion, resulting from our patient selection process.

\section{Surgical Procedure in Octogenarians}

In octogenarians, extensive surgical procedures for AAD (A) are associated with a high incidence of postoperative complications and considerable operative mortality. ${ }^{7}$ Generally, surgical procedures for AAD (A) are determined by both the extent of the dissection and the location of the entry tear. ${ }^{18}$ One study ${ }^{19}$ reported that $20 \%$ to $30 \%$ of AAD (A) cases required additional aortic arch repair according to 4 indications: the presence of an intimal tear in the arch, rupture of the arch, fragile tissue in the false lumen of the arch, or a fragmented false channel. Moreover, aortic root surgery, such as the bio-Bentall, David, or Yacoub technique, might be indicated when there are pathologic changes in the aortic valve or root. ${ }^{20}$ In recent reports of AAD (A) in octogenarians, Rylski and colleagues ${ }^{14}$ reported 8 patients $(9.4 \%)$ who were treated by total arch replacement and $11(13.3 \%)$ by aortic root surgery, with a 30 -day mortality of $34.9 \%$. El-Sayed Ahamed and colleagues ${ }^{15}$ reported 7 cases $(18 \%)$ of total arch replacement and $8(21 \%)$ of aortic root surgery, with a 30 -day mortality of $26 \%$. However, Hata and colleagues ${ }^{9}$ reported 27 AAD 
(A) cases in which no patient underwent total arch replacement or aortic root surgery; their in-hospital mortality was $3.7 \%$. Tang and colleagues ${ }^{10}$ also reported AAD (A) cases in which none was treated by total arch replacement and 1 $(5 \%)$ by aortic root surgery, with no in-hospital deaths. Similarly, in our study, only $4(5.2 \%)$ patients underwent total arch replacement and none was treated by aortic root surgery; the 30-day mortality was $6.5 \%$. These results suggest that when treating octogenarians for AAD (A), techniques that limit the aortic replacement site to the isolated ascending aorta may contribute to early survival benefits.

\section{Postoperative Aortic Events}

Although extensive procedures such as total arch replacement or aortic root surgery are intended to promote aortic remodeling and to reduce late complications associated with a patent false lumen, ${ }^{18,20}$ some reports indicate that replacing the arch during $\mathrm{AAD}(\mathrm{A})$ repair increases surgical risks such as bleeding or cerebral complications. ${ }^{18,20-22}$ However, there are no data indicating whether a limited or extended surgical strategy provides better early, mid-, and long-term results in octogenarians. Our strategy is to perform the simplest possible limited replacement procedure in initial AAD (A) surgery. Although we had 2 cases of postoperative aortic rupture of the distal arch within 30 days after the initial surgery, the total 30-day mortality was only $6.5 \%$ (5 patients). Moreover, there were no proximal redissection cases. Only 3 patients required additional surgery related to the aortic dissection, and all 3 were successfully treated using endovascular techniques. Therefore, when treating octogenarians, a simpler, limited replacement procedure in the initial AAD (A) operation and endovascular techniques for treating later complications may improve both early and long-term outcomes.

\section{Mid- and Long-Term Survival}

When treating $\mathrm{AAD}(\mathrm{A})$, the postoperative quality of life is an important consideration, especially for octogenarians. Two reports $^{9,10}$ quantitatively assessed octogenarian patients' postoperative quality of life using the RAND SF-36 health survey questionnaire and the Mini-Mental State Examination. Tang et al. ${ }^{10}$ reported that octogenarians who survived surgery did well emotionally and socially but had lower physical functioning scores than their younger counterparts. Although we did not quantitatively assess patients' postoperative quality of life, 44 patients $(57 \%)$ were discharged without additional institutional care, and 11 of the 23 patients discharged to rehabilitative hospitals were later discharged to their home. Moreover, our study showed favorable overall survival rates after emergency surgery for $A A D$ (A), with $82 \%$ surviving at 1 year and $62 \%$ at 5 years. The mean age of our surgery-treated patients was 83 years, and the predicted life expectancy of Japanese people at 83 years is 6.92 years for men and 9.36 years for women. ${ }^{23}$ Thus, a limited replacement surgical strategy may contribute to favorable midterm postoperative results in octogenarians.

\section{Limitations}

This study was conducted as a retrospective analysis of clinical experience over a 14-year period in a single suburban hospital in Japan. Japanese patients are more likely to have a lower body mass index than do Western patients, which may affect the frequency of operative comorbidities. We did not assess the octogenarian patients' postoperative quality of life quantitatively. We also did not perform a randomized comparison between isolated ascending aortic replacement and total arch replacement. Moreover, we did not perform randomized comparisons of surgical techniques with versus without cerebral perfusion, with deep versus moderate hypothermia, or use of an axillary versus femoral artery arterial cannulation site. The sample size was relatively small, although it is the second largest sample size among published studies of octogenarians with AAD (A).

\section{CONCLUSIONS}

Although more precise data are needed regarding the quality of life, long-term survival, and risk of an aortic event in octogenarians after the initial surgery for AAD (A), our surgical strategy for AAD (A) provided survival benefits for octogenarians. This strategy is to limit the replacement site of the ascending aorta to the supracoronary and the hemiarch whenever possible. Although our results do not deny the necessity of extensive surgery in some cases, such as total arch replacement or an aortic root operation, a meticulous patient selection strategy and simple limited replacement surgical procedures may improve the early and midterm results for octogenarians with AAD (A).

\section{Conflict of Interest Statement}

Authors have nothing to disclose with regard to commercial support.

\section{References}

1. United Nations Department of Economic and Social Affairs. World Population Ageing 2013. Available at: http://www.un.org/en/development/desa/population/ publications/index.shtml. Accessed September 25, 2015.

2. Ministry of Internal Affairs and Communications, Japan. Data derived from the Statistics Bureau. Available at: http://www.stat.go.jp/english/data/jinsui/2013np/ index.htm. Accessed September 25, 2015.

3. Mehta RH, Suzuki T, Hagan PG, Bossone E, Gilon D, Llovet A, et al. Predicting death in patients with acute type A aortic dissection; International Registry of Acute Aortic Dissection (IRAD) Investigators. Circulation. 2002;105:200-6.

4. Neri E, Toscano T, Massetti M, Capannini G, Carone E, Tucci E, et al. Operation for acute type A aortic dissection in octogenarians: is it justified? J Thorac Cardiovasc Surg. 2001;121:259-67.

5. Caus T, Frapier JM, Giorgi R, Aymard T, Riberi A, Albat B, et al. Clinical outcome after repair of acute type A dissection in patients over 70 years old Eur J Cardiothorac Surg. 2002;22:211-7.

6. Chavanon O, Costache V, Bach V, Kétata A, Durand M, Hacini R, et al. Preoperative predictive factors for mortality in acute type A aortic dissection: an institutional report on 217 consecutives cases. Interact Cardiovasc Thorac Surg. 2007 6:43-6. 
7. Piccardo A, Regesta T, Zannis K, Gariboldi V, Pansini S, Tapia M, et al. Outcomes after surgical treatment for type A acute aortic dissection in octogenarians: a multicenter study. Ann Thorac Surg. 2009;88:491-7.

8. Trimarchi S, Eagle KA, Nienaber CA, Rampoldi V, Jonker FH, De Vincentiis C, et al. Role of age in acute type A aortic dissection outcome: report from the International Registry of Acute Aortic Dissection (IRAD). J Thorac Cardiovasc Surg. 2010;140:784-9.

9. Hata M, Sezai A, Yoshitake I, Wakui S, Minami K, Shiono M. Midterm outcomes of rapid, minimally invasive resection of acute type A aortic dissection in octogenarians. Ann Thorac Surg. 2010;89:1860-4.

10. Tang GH, Malekan R, Yu CJ, Kai M, Lansman SL, Spielvogel D. Surgery for acute type A aortic dissection in octogenarians is justified. J Thorac Cardiovasc Surg. 2013;145:S186-90.

11. García-Rinaldi R, Carballido J, Mojica J, Soltero ER, Curcic S, Barceló J, et al. Surgical treatment of aortic dissections: initial experience with the adventitial inversion technique. Ann Thorac Surg. 1998;65:1255-9.

12. Kondoh H, Taniguchi K, Funatsu T, Toda K, Masai T, Takahashi T, et al. Total arch replacement with long elephant trunk anastomosed at the base of the innominate artery: a single-centre longitudinal experience. Eur J Cardiothorac Surg. 2012;42:840-8.

13. Iwasaki H, Satoh H, Ishizaka T, Matsuda H. Outcomes of single-stage total arch replacement via clamshell incision. J Cardiothorac Surg. 2011;6:114.

14. Rylski B, Suedkamp M, Beyersdorf F, Nitsch B, Hoffmann I, Blettner M, et al Outcome after surgery for acute aortic dissection type A in patients over 70 years: data analysis from the German Registry for Acute Aortic Dissection Type A (GERAADA). Eur J Cardiothorac Surg. 2011;40:435-40.

15. El-Sayed Ahmad A, Papadopoulos N, Detho F, Srndic E, Risteski P, Moritz A, et al. Surgical repair for acute type A aortic dissection in octogenarians. Ann Thorac Surg. 2015;99:547-51.

16. Geirsson A, Szeto WY, Pochettino A, McGarvey ML, Keane MG, Woo YJ, et al. Significance of malperfusion syndromes prior to contemporary surgical repair for acute type A dissection: outcomes and need for additional revascularizations. Eur J Cardiothorac Surg. 2007;32:255-62.

17. Santini F, Montalbano G, Casali G, Messina A, Iafrancesco M, Luciani GB, et al. Clinical presentation is the main predictor of in-hospital death for patients with acute type A aortic dissection admitted for surgical treatment: a 25 years experience. Int J Cardiol. 2007;115:305-11.

18. Roselli EE. We should replace the aortic arch and more in DeBakey type I dissection-a perspective from the Cleveland Clinic. Ann Cardiothorac Surg. 2013;2: 216-21

19. Kirklin JW, Kouchoukos NT. When and how to include arch repair in patients with acute dissections involving the ascending aorta. Semin Thorac Cardiovasc Surg. 1993;5:27-32.

20. Erbel R, Aboyans V, Boileau C, Bossone E, Bartolomeo RD, Eggebrecht H, et al. 2014 ESC Guidelines on the diagnosis and treatment of aortic diseases: document covering acute and chronic aortic diseases of the thoracic and abdominal aorta of the adult. The Task Force for the Diagnosis and Treatment of Aortic Diseases of the European Society of Cardiology (ESC). Eur Heart J. 2014;35: 2873-926.

21. Ando M, Nakajima N, Adachi S, Nakaya M, Kawashima Y. Simultaneous graft replacement of the ascending aorta and total aortic arch for type A aortic dissection. Ann Thorac Surg. 1994;57:669-76.

22. Ochiai Y, Imoto Y, Sakamoto M, Ueno Y, Sano T, Baba H, et al. Long-term effectiveness of total arch replacement for type A aortic dissection. Ann Thorac Surg. 2005;80:1297-302.

23. Ministry of Internal Affairs and Communications, Japan. Data derived from the Statistics Bureau. Available at: http://www.stat.go.jp/english/data/nenkan/143102.htm. Accessed September 25, 2015

Key Words: aortic dissection, octogenarian, proximal aortic replacement

Readers who found these articles interesting may also like to read the following papers found in recent and future issues of our sister publications, Seminars in Thoracic and Cardiovascular Surgery and Operative Techniques in Thoracic and Cardiovascular Surgery!

\section{Acquired: Aortic Disease}

Original Submission: Outcomes of Open Surgical Repair for Type B Dissecting Aortic Aneurysm with Alternative Methods in the Endovascular Stent Era. Mitsumasa Hata. Semin Thorac Cardiovasc Surg 2015; Summer; 27(2):106-112.

Editorial Commentary: It is Difficult to Compare Apples and Oranges: Acute and Chronic Type B Aortic Dissections, Complicated and Uncomplicated, are Different and Should be Treated as Such. Ourania Preventza. Semin Thorac Cardiovasc Surg 2015; Summer; 27(2):113-114.

News and Views: Treatment of Thoracic Aortic Aneurysm: Role of Earlier Intervention. Bulat A. Ziganshin. Semin Thorac Cardiovasc Surg 2015; Summer; 27(2);135-143.

Aortic root enlargement during aortic valve replacement: Nicks and Manouguian techniques. Kendra J Grub. Oper Tech Thorac Cardiovasc Surg 2015; Autumn; 20(3):206-218.

The Konno-Rastan procedure for anterior aortic annular enlargement. Mark E. Roeser. Oper Tech Thorac Cardiovasc Surg 2015: Autumn; 20(3):219-233. 